University of Nebraska - Lincoln

DigitalCommons@University of Nebraska - Lincoln

Ronald Cerny Publications

Published Research - Department of Chemistry

September 2006

\title{
Tau-tubulin kinase 1 (TTBK1), a neuron-specific tau kinase candidate, is involved in tau phosphorylation and aggregation
}

Shinji Sato

University of Nebraska Medical Center-Omaha, shinjisato@unmc.edu

Ronald Cerny

rcerny1@unl.edu

James L. Buescher

University of Nebraska Medical Center-Omaha

Tsuneya Ikezu

University of Nebraska Medical Center-Omaha, tikezu@unmc.edu

Follow this and additional works at: https://digitalcommons.unl.edu/chemistrycerny

Part of the Chemistry Commons

Sato, Shinji; Cerny, Ronald; Buescher, James L.; and Ikezu, Tsuneya, "Tau-tubulin kinase 1 (TTBK1), a neuron-specific tau kinase candidate, is involved in tau phosphorylation and aggregation" (2006). Ronald Cerny Publications. 3.

https://digitalcommons.unl.edu/chemistrycerny/3

This Article is brought to you for free and open access by the Published Research - Department of Chemistry at DigitalCommons@University of Nebraska - Lincoln. It has been accepted for inclusion in Ronald Cerny Publications by an authorized administrator of DigitalCommons@University of Nebraska - Lincoln. 
Published in Journal of Neurochemistry 98:5 (September 2006), pp. 1573-1584. doi:10.1111/j.1471-4159.2006.04059.x Copyright @ 2006 Shinji Sato, Ronald L. Cerny, James L. Buescher, and Tsuneya Ikezu. Submitted March 16, 2006; revised April 24, 2006; accepted April 24, 2006; published online July 24, 2006.

\title{
Tau-tubulin kinase 1 (TTBK1), a neuron-specific tau kinase candidate, is involved in tau phosphorylation and aggregation
}

\author{
Shinji Sato ${ }^{1}$, Ronald L. Cerny ${ }^{2}$, James L. Buescher ${ }^{1}$, and Tsuneya Ikezu ${ }^{1,3}$ \\ ${ }^{1}$ Center for Neurovirology and Neurodegenerative Disorders, Department of Pharmacology and Experimental Neuroscience, University of \\ Nebraska Medical Center, Omaha, Nebraska \\ ${ }^{2}$ Department of Chemistry, University of Nebraska-Lincoln, Lincoln, Nebraska \\ ${ }^{3}$ Corresponding author. Email: tikezu@unmc.edu
}

\begin{abstract}
Neurofibrillary tangles, which are major pathological hallmarks of Alzheimer's disease (AD), are composed of paired helical filaments (PHFs) containing hyperphosphorylated tau. Specific kinases regulate tau phosphorylation and are closely linked to the pathogenesis of $A D$. We have characterized a human tau-tubulin kinase 1 (TTBK1) gene located on chromosome 6p21.1. TTBK1 is a serine/threonine/tyrosine kinase that is conserved among species and belongs to the casein kinase 1 superfamily. It is specifically expressed in the brain, especially in the cytoplasm of cortical and hippocampal neurons. TTBK1 phosphorylates tau proteins in both a $\mathrm{Mg}^{2+}$ - and a $\mathrm{Mn}^{2+}$-dependent manner. Phosphopeptide mapping and immunoblotting analysis confirmed a direct tau phosphorylation by TTBK1 at Ser198, Ser199, Ser202 and Ser422, which are also phosphorylated in PHFs. TTBK1 also induces tau aggregation in human neuronal cells in a dose-dependent manner. We conclude that TTBK1 is a neuron-specific dual kinase involved in tau phosphorylation at AD-related sites and is also associated with tau aggregation.
\end{abstract}

Keywords: aggregation, Alzheimer's disease, molecular cloning, phosphorylation, protein kinase, tau protein.

Neurofibrillary tangles (NFTs) are pathologic hallmarks of Alzheimer's disease (AD) and other neurodegenerative diseases called 'tauopathies' (Lee et al. 2001). NFTs contain abnormal paired helical filaments (PHFs), of which the primary component is hyperphosphorylated tau protein (PHF-tau) (Grundke-Iqbal et al. 1986; Buee et al. 2000; Lee et al. 2001). NFTs are also found in the brain of patients with frontotemporal dementia and Parkinsonism linked to chromosome 17 (FTDP-17), a neurodegenerative disease caused by autosomal dominant mutations in the tau gene (Hutton et al. 1998). Because phosphorylation of specific sites of the tau gene reduces its affinity for microtubules, the phosphorylation of tau is a critical modification required for NFT formation (Biernat et al. 1993; Bramblett et al. 1993) and the induction of self-aggregation (Alonso et al. 1996; Alonso et al. 2001).

A number of protein kinases have been studied in investigating the molecular mechanism of tau phosphorylation (Planel et al. 2002). Among them, the glycogen synthase kinase $3 \beta$ (GSK3 $\beta$ ) and cyclin-depen- dent protein kinase CDK5/p25 complexes are well characterized. They have been biochemically isolated as kinases that can phosphorylate tau proteins at multiple Ser/Thr residues found in PHF-tau, and their expressions are up-regulated in the brain of patients with AD (Ishiguro et al. 1992; Arioka et al. 1993; Imahori and Uchida 1997; Patrick et al. 1999). Over-expression of CDK 5 activator p 25 in mouse and GSK3 $\beta$ in fly enhances tau aggregation in vivo (Jackson et al. 2002;

Abbreviations: Abs, antibodies; AD, Alzheimer's disease; $\mathrm{CDK}$, cyclin-dependent protein kinase; CK, casein kinase; $\mathrm{Cq}$, chloroquine; DMEM, Dulbecco's modified Eagle's medium; FBS, fetal bovine serum; FTDP-17, frontotemporal dementia and Parkinsonism linked to chromosome 17; GSK3, glycogen synthase kinase 3; HEK293cells, human embryonic kidney cells; mAb, monoclonal antibody; MW, molecular weight; NFT, neurofibrillary tangles; pAb, polyclonal antibody; PBS, phosphatebuffered saline; PHF, paired helical filaments; SDS-PAGE, sodium dodecyl sulfate-polyacrylamide gel electrophoresis; TTBK1, tau-tubulin kinase 1; TTBK1cat, catalytic domain of recombinant TTBK1; TTK, tau-tubulin kinase. 
Noble et al. 2003), suggesting that up-regulation of tau kinase can either cause or enhance tau aggregation.

In addition to such Ser/Thr residues, recent studies have demonstrated that PHF-tau is also phosphorylated at Tyr residues (Tyr18, 197 and 394 of 2N/4R tau) in the brain of patients with AD (Lee et al. 2004; Bhaskar et al. 2005; Derkinderen et al. 2005; Vega et al. 2005) and in animal models of FTDP-17 (Lee et al. 2004; Bhaskar et al. 2005; Vega et al. 2005). These findings suggested that not only Ser/Thr phosphorylation but also Tyr phosphorylation of tau protein is involved in NFT formation. Yet, the way in which Tyr phosphorylation of tau protein alters its affinity for aggregation has not yet been determined. Although the sarcoma family of nonreceptor tyrosine kinases (src)-like Tyr kinase family, e.g. Fyn and c-Abl, can phosphorylate Tyr18 and Tyr394 (Lee et al. 2004; Derkinderen et al. 2005), no kinase has been reported to phosphorylate Tyr197. In addition, the known tau kinases are not specific to neurons where some cell type-specific molecular mechanism should exist for the PHF-tau and NFT formation.

Thus, the identification of a neuron-specific kinase, which is involved in PHF-tau formation, will enhance the understanding of the mechanism of NFT formation. We have screened genes that are relatively specifically expressed in human brain and have conserved protein kinase domain and identified a neuron-specific kinase. It has been deposited as tau-tubulin kinase 1 (TTBK1), which encodes a Ser/Thr/Tyr protein kinase motif and a polyglutamate region. Although the bovine homolog of the protein has been characterized as a tau-tubulin kinase (TTK), the published mouse-homolog sequence contained an error and was translated in a form truncated immediately after the kinase domain (Tomizawa et al. 2001). Thus, there is no characterization of fulllength TTBK1. TTBK1 is highly homologous to TTBK2 and is among the closest relatives of casein kinase CK1 in the CK1 kinase group, which consists of the CK1, TTBK and VRK families (Manning et al. 2002). CK1 $\delta$ is known to be up-regulated in AD brain and can induce tau phosphorylation in vitro ( $\mathrm{Li}$ et al. 2004), whereas full-length TTBK2 has never been investigated. TTBK1 can directly phosphorylate tau protein in vitro and in intact cells at Ser198, Ser199, Ser202 and Ser422 sites. TTBK1 also induces tau aggregation in SH-SY5Y cells.

\section{Materials and methods}

\section{5'-RACE of TTBK1 CDNA}

To find the 5' end of the cDNA of the human TTBK1 gene, we employed a GeneRacer kit (Invitrogen, Carlsbad, CA, USA) with human cortex poly(A) ${ }^{+}$RNA isolated by Trizol reagent (Invitrogen) and the protocols supplied by the manufacturer. Reverse transcription was performed using a gene-specific primer 24289 (5'-TGGCCTCGATGGACTCCAAGATCTGCTT-3'). The cDNA product was subjected to PCR using a set of PCR primers (GeneRacer 5'Primer and 24289; Invitrogen) and $P f u$ Turbo DNA polymerase (Stratagene, La Jolla, CA, USA). The PCR conditions were as follows: $2 \mathrm{~min}$ at $94^{\circ} \mathrm{C}$, followed by 25 cycles of $30 \mathrm{~s}$ at $94^{\circ} \mathrm{C}, 30 \mathrm{~s}$ at $65^{\circ} \mathrm{C}$ and $2 \mathrm{~min}$ at $72^{\circ} \mathrm{C}$, with $15 \mathrm{~min}$ at $72^{\circ} \mathrm{C}$ and then held at $4^{\circ} \mathrm{C}$. The PCR products were subjected to nested PCR using a set of primers (GeneRacer Nested 5' Primer and 24290: 5'-CAAGATCTGCTTGCCCAGCCGCAA-3') using Pfu Turbo. The PCR conditions were the same as described for the first PCR. The resultant DNA bands were agarose-purified and cloned into pCR4-TOPO vector using the TOPO Cloning kit (Invitrogen). The sequenced subcloned PCR fragments (named RACE500) corresponded to the open reading frame (ORF) region of the KIAA1855 gene.

To generate full-length TTBK1, the RACE500 fragment from the pCR4-TOPO vector was hybridized with an equimolar quantity of vector containing KIAA1855 in pBluescript (Kazusa DNA Institute, Kisarazu, Chiba, Japan), followed by DNA polymerization using Herculase DNA polymerase (Stratagene) to generate a DNA template for the $\mathrm{NH}_{2}$ terminal of TTBK1. The PCR conditions were as follows: $5 \mathrm{~min}$ at $94^{\circ} \mathrm{C}$, followed by 10 cycles of $30 \mathrm{~s}$ at $94^{\circ} \mathrm{C}, 30 \mathrm{~s}$ at $65^{\circ} \mathrm{C}$ and $5 \mathrm{~min}$ at $72^{\circ} \mathrm{C}$, followed by $15 \mathrm{~min}$ at $72^{\circ} \mathrm{C}$ and then held at $4^{\circ} \mathrm{C}$. The fused RACE500/KIAA1855 template was subjected to PCR using a primer set (23266, 5'-GAAGTCCTTGAGCTCCGTCTC-3'; 25022, 5'-ACGCGTCGACATATGCAGTGCCTAGCGGCCGCCCTT-3') and Herculase. The PCR conditions were as follows: $2 \mathrm{~min}$ at $94^{\circ} \mathrm{C}$, followed by 30 cycles of $30 \mathrm{~s}$ at $94^{\circ} \mathrm{C}, 30 \mathrm{~s}$ at $65^{\circ} \mathrm{C}$ and $2 \mathrm{~min}$ at $72^{\circ} \mathrm{C}$ ), followed by $15 \mathrm{~min}$ at $72^{\circ} \mathrm{C}$ and then held at $4^{\circ} \mathrm{C}$. The resultant product was subjected to expression vector construction of full-length TTBK1. The entire sequence was confirmed through DNA sequencing using a set of 15 primers.

\section{Bioinformatic analysis}

Amino acid sequences were obtained from KinBase (http://kinase.

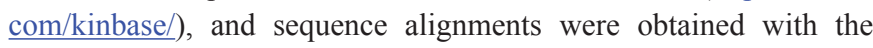
ClustalW program (Thompson et al. 1994). The phylogenetic tree was computed with ClustalW by the neighbor joining method with Kimura's correlation (bootstrap scores for 1000 iterations). The tree was displayed using a TreeView program (Rogers et al. 1986). The PESTfind program (http://bioweb.pasteur.fr/seqanal/interfaces/pestfind-simple.html) was used for the PEST sequence search.

\section{Northern blot}

The FirstChoice ${ }^{\circledR}$ human total RNA survey panel (Ambion, Autsin, TX, USA) and human total RNA panel IV (BD Biosciences, San Jose, CA, USA) were used for the northern blot analysis. The northern blot was hybridized with a ${ }^{32} \mathrm{P}$-labeled cDNA probe derived from the 3'non-coding region of TTBK1 cDNA using DNA labeling beads (Amersham Biosciences, Piscataway, NJ, USA) according to the manufacturer's instructions. The membranes were exposed to Phosphoscreen, and the images were scanned by Typhoon (Amersham Biosciences).

\section{In situ hybridization}

The location of mouse TTBK1 mRNA was determined on cryosections $(10 \mu \mathrm{m})$ of brain from adult C57/BL6 mice. For in vitro transcription, the digoxigenin RNA-labeling kit (Roche Molecular Biochemicals, In- 
dianapolis, IN, USA) was used with pBluscript SK(-) vector (Stratagene) containing the 291-bp mouse TTBK1 PCR product cloned into it's $X h o I-E c o R I$ sites as the template. Labeled probes, corresponding to nucleotides 2400-2690 (counted from the ATG start codon), were transcribed in either sense or antisense orientation, using either T7 or T3 polymerases, respectively. The pre-hybridized sections were then hybrizided with digoxigenin-labeled RNA probes, washed, incubated with alkaline phosphatase-conjugated anti-DIG Fab fragments (Roche) and diluted to $1: 500$ following the manufacturer's instructions (Roche). After washing with Tris-buffered saline, $\mathrm{pH}$ 9.0, sections were incubated overnight in substrate solution (nitro-blue tetrazolium/5-bromo-4-chloro-3-indolylphosphate; Roche). The sections were then counterstained with Hoechst 33342 (Invitrogen), and mounted with Vectashield (Vector Laboratories, Burlingame, CA, USA). Phasecontrast and fluorescence microscopy were performed using a microscope (Eclipse TE300; Nikon Instruments, Melville, NY, USA) with Plan Apo 2×/0.1, Plan-fluor ELWD 20×/0.45 and Plan-fluor ELWD $60 \times / 0.70$ objectives (Nikon) with a DVC-1310 digital camera and Cview imaging software (DVC Company, Austin, TX, USA).

\section{Cell cultures}

SH-SY5Y cells obtained from the American Type Culture Collection (ATCC, Manassas, VA, USA) were cultured in a $1: 1$ mixture of Dulbecco's modified Eagle's medium (DMEM) and Ham's F12 supplemented with $10 \%$ fetal bovine serum (FBS), $10 \mathrm{U} / \mathrm{mL}$ penicillin and $10 \mu \mathrm{g} / \mathrm{mL}$ streptomycin (all reagents were purchased from Invitrogen). African green monkey kidney cells (COS-7) and human embryonic kidney cells (HEK293 cells) were cultured in DMEM supplemented with $10 \%$ FBS. Both types of cell cultures were grown in a humidified $5 \%(\mathrm{v} / \mathrm{v}) \mathrm{CO}_{2} /$ air environment at $37^{\circ} \mathrm{C}$.

\section{Vector construction and transfection}

The cDNA encoding the full length of TTBK1 (1321 amino acids) was inserted into pcDNA3.1 $1^{+}$(Invitrogen) with synthetic linkers, which fused an $\mathrm{NH}_{2}$-terminal influenza hemagglutinin protein (HA)-epitope tag with a Kozac sequence (Kozak 1986). The full-length human tau cDNA (htau40, the longest 2N/4R isoform kindly provided by Dr K. Paudel, Sir Mortimer B. Davis-Jewish General Hospital, Montreal, QC, Canada) was cloned into pcDNA3.1 $1^{+}$. COS-7 cells were transiently transfected using FuGENE 6 (Roche) according to the manufacturer's instructions. Forty-eight hours after transfection, cells were lysed in Tris-buffered saline containing Triton X-100 (TBST) buffer (50 mm Tris-Cl pH 7.4, $150 \mathrm{~mm} \mathrm{NaCl}, 2 \mathrm{mM}$ EDTA, 10\% Glycerol and 1\% Triton X-100) containing phosphatase and protease inhibitors. Lysates were centrifuged at $20000 \mathrm{~g}$. The supernatants, after the protein concentration was determined by a BCA assay kit (Pierce, Rockford, IL, USA), were used for immunoblotting and immunoprecipitation.

\section{Recombinant adenovirus}

A recombinant adenovirus encoding HA-TTBK1-1321 (Ad-HATTBK1-1321) was constructed using the AdEasy system (He et al. 1998). HA-TTBK1 was excised from pcDNA3.1 using BamHI and $X b a \mathrm{I}$, and was directionally subcloned into the pShuttle-CMV at its $B g l \mathrm{II}$ and $X b a \mathrm{I}$ restriction sites. Successful recombinants of pShuttleCMV were transformed by electroporation along with the adenoviral backbone vector pAdEasy-1 into BJ5183 cells. Viral production, pu- rification and quantification were performed using HEK293 cells and $\mathrm{CsCl}$ ultracentrifugation as previously described (He et al. 1998). The adenoviral vector encoding full-length human tau (Ad-htau40) was a kind gift from Dr A. Takashima (Riken Brain Science Institute, Wako-Shi, Saitama, Japan) (Sato et al. 2002). Adenoviral vector expressing green fluorescent protein (Ad-GFP) has been described in detail elsewhere (Ikezu et al. 2003).

\section{Recombinant protein purification}

6×His-tagged TTBK1 kinase domain (amino acids 38-319, TTB$\mathrm{K} 1$ cat) was subcloned into the NdeI-XhoI sites of the pET28a vector (BD Biosciences) and transformed to BL21DE3 (BD Biosciences) containing pG-Tf2 vector (TaKaRa; Mirus Bio, Madison, WI, USA), which expresses TF and GroEL-GroES chaperone proteins. After $3 \mathrm{~h}$ of incubation with $1 \mathrm{~mm}$ isopropyl thiogalactoside (dioxane-free; Sigma, St Louis, MO, USA) at $37^{\circ} \mathrm{C}$, cells were harvested, sonicated in lysis buffer (50 mm NaH${ }_{2} \mathrm{PO}_{4}, \mathrm{pH} 8.0,300 \mathrm{~mm} \mathrm{NaCl}, 10 \mathrm{~mm}$ imidazole, 1\% Triton X-100, $20 \mathrm{~mm}$ 2-mercaptoethanol) containing protease inhibitors and centrifuged at $40000 \mathrm{~g}$ for $30 \mathrm{~min}$ in order to collect supernatant. The recombinant protein was batch-purified from the supernatant with Ni-NTA His Bind Resin (BD Biosciences), dialyzed against buffer $\mathrm{A}(20 \mathrm{~mm}$ Tris- $\mathrm{HCl}, \mathrm{pH} 8.0$ and 10\% glycerol), and loaded onto HiTrap Q HP column (equilibrated in buffer A; Amersham Biosciences) connected to a fast protein liquid chromatograph (ÄKTA FPLC system; Amersham Biosciences). The bound protein was eluted with a $0-1.0 \mathrm{~m}$ gradient of $\mathrm{NaCl}$. The fraction containing eluted protein was concentrated using a centrifugal filter device (Centricon YM30; Millipore Amicon, Bedford, MA, USA), and dialyzed with storage buffer (20 mm Tris-HCl, $\mathrm{pH} 7.0,250 \mathrm{~mm}$ $\mathrm{NaCl}, 1 \mathrm{~mm}$ EGTA, $1 \mathrm{~mm}$ EDTA, $10 \mathrm{~mm}$ 2-mercaptoethanol, 50\% glycerol and $0.1 \%$ Triton $\mathrm{X}-100$ ) for kinase assays.

\section{In vitro protein kinase assay}

The TTBK1 kinase domain fragment (TTBK1cat, $60 \mathrm{ng}$ ) was incubated with $500 \mathrm{ng}$ of htau40 in $20 \mu \mathrm{L}$ of kinase buffer $(20 \mathrm{~mm}$ Tris$\mathrm{HCl}, \mathrm{pH} 7.5,100 \mu \mathrm{m} \mathrm{ATP}$ and $5 \mathrm{~mm}$ dithiothreitol) supplemented with $1 \mu \mathrm{Ci}\left[\gamma_{-}{ }^{32} \mathrm{P}\right] \mathrm{ATP}$ (Amersham Biosciences) in the presence of $10 \mathrm{~mm}$ of either $\mathrm{MgCl}_{2}$ or $\mathrm{MnCl}_{2}$ at $30^{\circ} \mathrm{C}$ for up to $2 \mathrm{~h}$. All reactions were stopped by adding $10 \mu \mathrm{L}$ of $2 \times$ Laemmli sample buffer and boiling for $5 \mathrm{~min}$. Following sodium dodecyl sulfate-polyacrylamide gel electrophoresis (SDS-PAGE), gels were stained with Coomassie Brilliant Blue R-250 (CBB; FisherBiotech, Fairlawn, NJ, USA) and dried for autoradiography. The radioactive bands were cut from the gel and the radioactivity was quantified by a liquid scintillation counter (PerkinElmer, Wellesley, MA, USA). The kinetics of the phosphorylation were analyzed using the best-fit program of Prism v4 (GraphPad Software, San Diego, CA, USA).

\section{Liquid chromatography/tandem mass spectrometry (LC/MS/MS)} Purified TTBK1cat (120 ng) was incubated with $1 \mu \mathrm{g}$ of htau40 in $40 \mu \mathrm{L}$ of kinase buffer in the presence of either $10 \mathrm{~mm} \mathrm{MgCl}_{2}$ or $10 \mathrm{~mm} \mathrm{MnCl}_{2}$ at $30^{\circ} \mathrm{C}$ overnight. The samples were separated by SDS-PAGE and the stained bands were cut out and subjected to LC/MS/MS analysis as described previously (Kayser et al. 2004). Briefly, gel pieces were digested by trypsin (Promega, Madison, WI, USA) and the digested peptides were extracted in 5\% formic 
acid $/ 50 \%$ acetonitrile and separated using $\mathrm{C} 18$ reversed phase LC column (Dionex, Sunnyvale, CA, USA).

A Q-TOF Ultima tandem mass spectrometer (Waters, Milford, MA, USA) with electrospray ionization was used to analyze the eluting peptides. The system was user-controlled employing the MassLynx software v3.5 (Waters) in data-dependant acquisition mode with a 1-s survey scan (380-1900 D) followed by up to three, 2.4-s MS/ MS acquisitions (60-1900 D). The instrument was operated at a mass resolution of 8000 and was calibrated using the fragment ion masses of doubly protonated Glu-fibrinopeptides.

Database searches of the acquired MS/MS spectra were performed using Mascot v1.9.0 (Matrix Science, Manchester, UK). The database was restricted to human proteins. The search parameters were: no restrictions on either protein molecular weight or pI, enzymatic specificity was set to trypsin and phosphorylation was allowed as a variable peptide modification. Only peptides that gave a Mascot score greater than $13(p<0.05)$ for phosphorylated forms were considered as positive identifications.

\section{Isolation of sarkosyl-insoluble Tau}

Sarkosyl extracts were prepared as described previously (Goedert et al. 1992) with slight modifications. Briefly, SH-SY5Y cells, infected with adenovirus ( 0.5 multiplicity of infection [MOI] of Ad-htau40 and 0-10 MOI of either Ad-HA-TTBK1-1321 or Ad-GFP), were homogenized in sucrose buffer (50 mm Tris- $\mathrm{HCl}, \mathrm{pH} 7.4,0.8 \mathrm{~m} \mathrm{NaCl}$, $1 \mathrm{~mm}$ EGTA and 10\% sucrose) containing phosphatase and protease inhibitors. The homogenates were centrifuged at $20000 \mathrm{~g}$ for $20 \mathrm{~min}$ at $4{ }^{\circ} \mathrm{C}$. The supernatants were mixed to a final concentration of $1 \%$ sarkosyl and incubated for $1 \mathrm{~h}$ at $37^{\circ} \mathrm{C}$ with gentle shaking. After ultracentrifugation at $100000 \mathrm{~g}$ for $60 \mathrm{~min}$ (TL-100; Beckman Coulter, Fullerton, CA, USA), the sarkosyl-insoluble pellets were resuspended in $2 \times$ Laemmli sample buffer for SDS-PAGE and immunoblotting.

\section{Immunoblot analysis and antibodies}

Proteins were separated by SDS-PAGE, transferred to ImmobilonP membrane (Millipore Amicon), and blocked by blocking buffer (SuperBlock with 5\% skimmed milk; Pierce). The following antibodies (Abs) were used for immunoblotting: $\alpha$-HA monoclonal Ab (HA mAb, 1 : 10 000; Sigma); $\alpha$-GFP mAb (1 : 3000; BD Biosciences); $\alpha$-tau T46 mAb (specific to tau 404-441, $1: 1000$; Invitrogen); Tau-5 mAb (middle of tau, 1: 1000; BD Biosciences); AT8 (phospho-Ser199, Ser202 and Thr205 specific polyclonal Ab, pAb, 1 : 500; Innogenetics, Gent, Belgium); CP13 mAb (phosphoSer202 specific, $1: 250$, a gift from Dr P. Davies, Albert Einstein College of Medicine, Bronx, NY, USA); and pSer422 pAb (phospho-Ser422 specific, 1 : 1000, a gift from Dr A. Delacourte, Lille, France). A TTBK1-specific rabbit polyclonal antiserum (7589 pAb) was raised against a synthetic peptide, FDWEKAGTDALLST, of TTBK1308-321 (Alpha Diagnostic Intl, San Antonio, TX, USA), purified with a protein-G sepharose FF column (Amersham Biosciences) and used at $1: 3000(0.6 \mu \mathrm{g} / \mathrm{mL})$.

Immunofluorescence and confocal laser-scanning microscopy COS-7 cells $\left(1 \times 10^{4} /\right.$ well $)$ were plated on poly-d-Lysine-coated 8 -well LAB-TEK chamber slides (Nunc, Rochester, NY, USA) and transfected with pcDNA3.1-HA-TTBK1 using FuGENE 6 (Roche). After 48 h the transfected cells were fixed in 4\% paraformaldehyde, and permeabilized in $0.1 \%$ Triton X-100 in phosphate-buffered saline (PBS). After blocking with $10 \%$ normal goat serum, the cells were incubated with $\alpha$-HA mAb (1 : 1000; Sigma) and 7589 pAb (1:300), followed by incubation with either Alexa488- or Alexa594-conjugated secondary antibodies (Invitrogen), counterstained with Hoechst 33342 (Invitrogen), and mounted with Vectashield (Vector Laboratories) and cover glass. Digital images were taken with a Nikon TE300 inverted fluorescence microscope (Nikon) using a Plan-fluor ELWD 40×/0.60 objective (Nikon) as previously described (Yamamoto et al. 2005).

A confocal laser-scanning microscopic study was performed using $4 \%$ paraformaldehyde-perfused mouse brain and $4 \%$ formalin-fixed human frontal cortex. Frozen sections $(30-\mu \mathrm{m}$ thick) were chemically bleached to reduce autofluorescence following the method described by Sun et al. (2002), blocked with 10\% normal goat serum containing $1 \%$ Triton $\mathrm{X}-100$ in PBS, and incubated with primary antibodies, $\alpha$-tubulin- $\beta 3 \mathrm{mAb}(1: 1000$; Promega) and $7589 \mathrm{pAb}$ ( $1: 300)$, followed by incubation with either Alexa488- or Alexa568conjugated secondary antibodies, counterstained with TOPRO-3 (Invitrogen) for nuclear staining, and mounted on glass slides as previously described (Yamamoto et al. 2005). The digital images were captured with a Zeiss LSM410 and 100×/0.30 (oil objective; Carl Zeiss AG, Göttingen, Germany).

\section{Statistical analysis}

All data were normally distributed. In case of multiple mean comparisons, data were analyzed by analysis of variances (anova), followed by the Newman-Keuls multiple comparison tests using statistics software (Prism v4.0; Graphpad Software). In the case of a single mean comparison, data were analyzed by Student's $t$-test. Values of $p$ less than 0.05 were regarded as significant.

\section{Results}

\section{Structure of the human TTBK1 gene}

We isolated the full-length cDNA by 5 ' rapid amplification of cDNA ends based on the human KIAA1855 gene. This cDNA was identical to the tau-tubulin kinase 1 (TTBK1) derived from an automated computational analysis 'kinome' project (Manning et al. 2002). TTBK1 is located on human chromosome 6p21.1 and is composed of 14 exons and 15 introns with a cDNA length of $6932 \mathrm{bp}$. The TTBK1 protein is 1321 amino acids in length, has a kinase domain, and a unique polyglutamate domain in the middle region of the sequence (Fig. 1a). Human TTBK1 homologs were found in mice, Caenorhabditis elegans and Drosophila melanogaster, the shorter non-catalytic regions of which are non-homologous to human TTBK1 (Fig. 1a).

Phylogenetic tree analysis among the CK1 group, which consists of CK1, TTBK and VRK families, showed that TTBK1 is highly homologous to TTBK2 (Fig. 1b). Among the CK1 group, CK1 $\delta$ can phosphorylate tau in vitro and in cultured cells (Li et al. 2004). The alignment of the kinase domain of TTBK1 and CK1 $\delta$ 


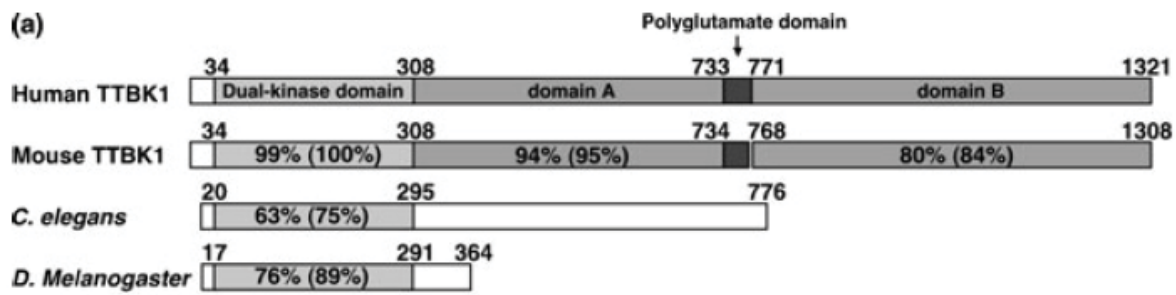

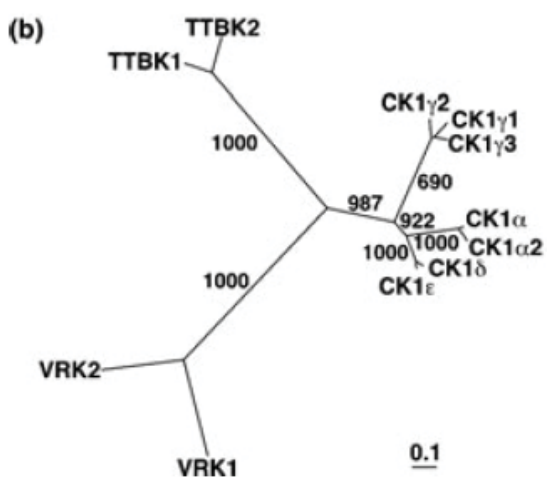

Figure 1. Multiple sequence alignment with tau-tubulin kinase 1 (TTBK1) and its orthologues. (a) Alignment of human and mouse TTBK1, and Caenorhabditis elegans and Drosophila melanogaster TTBK (KinBase ID: 16054, 11247, 11973 and 9447, respectively). TTBK1 34-308, dual-kinase domain; 309-732, conserved domain A; 733-770, polyglutamate domain; 771-1308, conserved domain B. Numbers in the diagrams are the percentage homology and similarity

showed a modest identity of $38 \%$ (52\% homology, Fig. 1c). These results suggest that TTBK1 is the closest relative of CK1, but not a member of CK1 family.

\section{Characterization of TTBK1 $\mathrm{mRNA}$ and protein ex- pression}

To determine the distribution of the TTBK1 gene, northern blotting of a multiple human tissue panel was conducted using a probe for human TTBK1(Fig. 2a). TTBK1 mRNA was detected as a $7.5-\mathrm{kb}$ mRNA band in adult brain cortex and cerebellum (lanes 1 and 2) and fetal brain tissue (lane 23, arrow). This is similar to the sequence length of human TTBK1, confirming its brain specificity from the fetal stage. In addition, a weak expression of TTBK1 was detected in both the spinal cord and testis in an image obtained with longer exposure (data not shown). No significant expression was detected in any of the other tissues.

In situ hybridization of mouse brain was performed to determine the distribution of TTBK1 gene expression in the brain. The cortical layers, the CA1 layers of the hippocampus, and the granular layer of cerebellum were strongly labeled with the mouse TTBKI complementary RNA (cRNA) probe (Figs $2 b-f$ ). Signals were also observed in the perinuclear and cytoplasmic regions of the large cortical pyramidal cells in the temporal cortex (Fig. 2b). Signals were also seen in the CA1 pyramidal neurons (Figs $2 \mathrm{c}$ and $\mathrm{d}$ ) and cerebellum granular neu- in parenthesis to human TTBK1. (b) Phylogenetic tree of the human casein kinase (CK) family using clustal $\mathrm{W}$ and TreeViewer programs. The scale bar represents 0.1 amino acid substitution per site. Bootstrap values (1000 bootstrap iterations) are indicated. Vaccinia related kinase 3 (VRK3) was removed because of its low homology to other kinases in the CK1 group. (C) The comparison of catalytic domains of TTBK1 and human CK1ס (KinBase ID: 14657).

rons (Figs 2e and f). The control sense probe showed no hybridization, and the TTBK1 probe did not cross-react with TTBK2 (data not shown). These data suggest the expression of the TTBK1 gene is specific to neurons.

\section{TTBK1 protein expression in neurons}

To detect the expression of TTBK1 protein, we prepared a rabbit polyclonal antibody (7589 pAb) raised against a synthetic peptide corresponding to the residues 308-321 of TTBK1 that are conserved in both humans and mice (see Materials and methods). The specificity of 7589 has been confirmed by both immunoblotting and immunocytochemistry (Fig. 3).

Frozen sections of human and mouse cortex were probed with antibodies to a neuronal marker, tubulin$\beta 3$ (Figs 4a, d, e, f, i and $\mathrm{j}$ in green), and 7589 (Figs 4b, $\mathrm{d}$, e, $\mathrm{g}, \mathrm{I}$ and $\mathrm{j}$ in red) for confocal laser-scanning microscopic imaging. The 7589-immunoreactive cells were mainly co-localized with tubulin- $\beta 3$-positive neurons in human (Figs $4 \mathrm{a}-\mathrm{d}$, arrowheads) and mouse cortex (Figs $4 \mathrm{e}-\mathrm{h}$, arrowheads), and the immunoreactivity was diminished by pre-incubation of 7589 with the antigen peptide (data not shown). These data indicated that TTBK1 is present in neurons.

To determine the actual molecular weight (MW) of TTBK1, HA- and myc-tagged full-length TTBK1 (HATTBK1) was expressed in COS-7 cells and detect- 

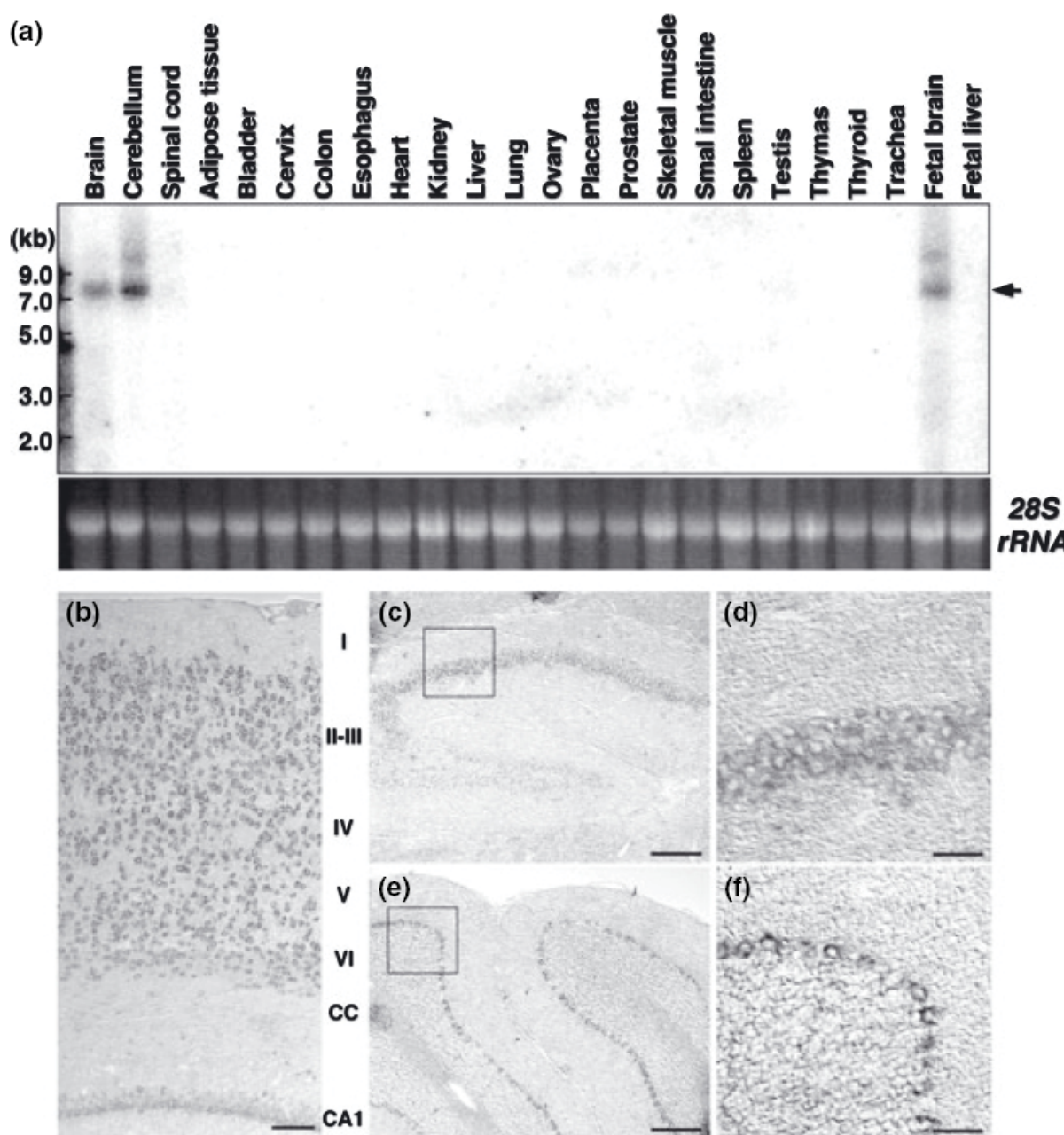

Figure 2. Tissue distribution of TTBK1 mRNA and its protein expression. (a) Northern blot of human multiple tissue total RNA panel for tau-tubulin kinase 1 (TTBK1) mRNA. The arrow points to a specific TTBK1 mRNA band $(7.5 \mathrm{~kb})$ in the brain and the cerebellum (upper panel). Ethidium bromide staining of $28 S$ rRNA (lower panel). (b-f) In situ hybridization of TTBK1 mRNA. (b) Coronal sections of adult mouse brain probed with mouse TTBK1 antisense complementary RNA. Mouse TTBK1 mRNA expression is observed in the frontal cortical layers (II$\mathrm{VI}$ ) and CA1 region of the hippocampus. CC, corpus callosum. (c) The CA1 region of the hippocampus. (d) Magnification of the inset in (c); the pyramidal layer of CA1. (e) Granular layer of the cerebellum. (f) Magnification of the inset in (e). Scale bars: (b) $100 \mu \mathrm{m}$; (c and e), $200 \mu \mathrm{m}$; (d and f), $50 \mu \mathrm{m}$.
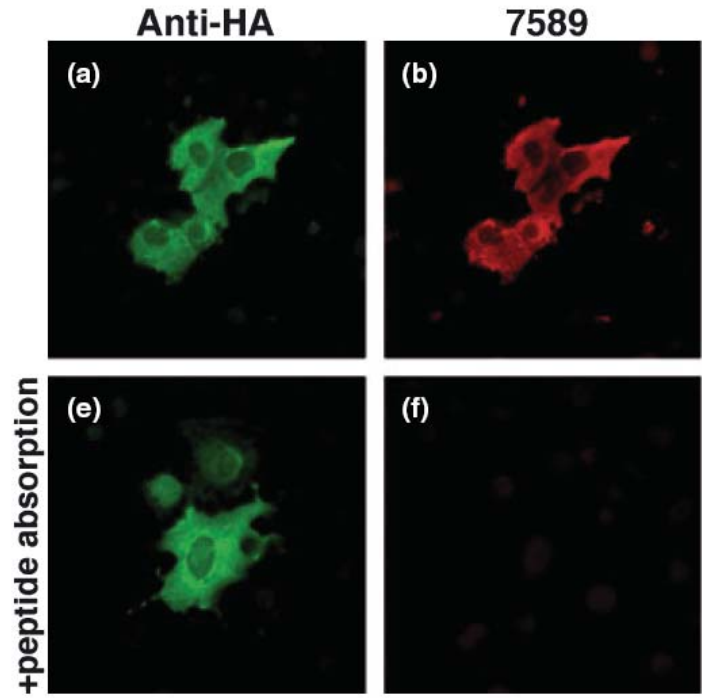

Figure 3. Immunofluorescent staining of tau-tubulin kinase 1 (TTBK1) by 7589 in transfected cells. (a-h) The detection of HA-TTBK1 by 7589 polyclonal antibodody (pAb) in COS-7 cells by double-immunostaining with anti-HA monoclonal antibody (mAb) (a and e, green) and 7589 pAb (b and f, red). Pre-absorption of 7589 pAb with the synthet-
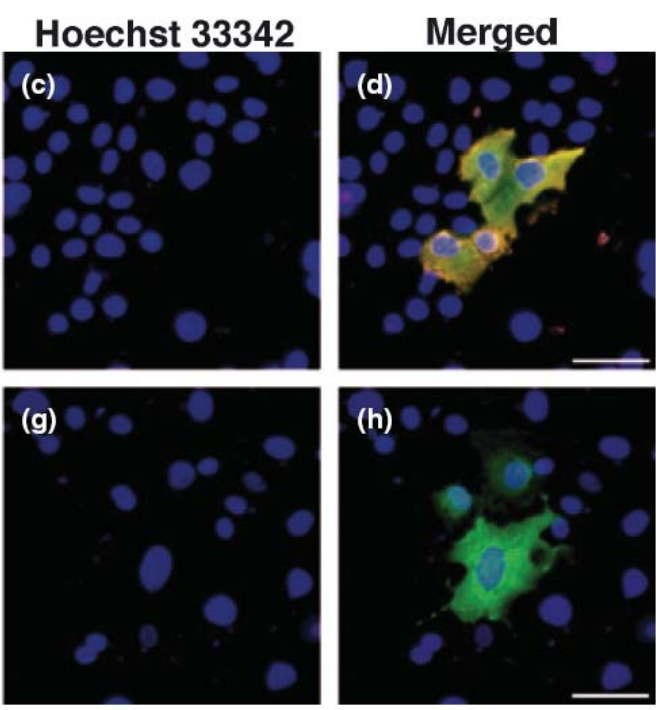

ic antigen peptide resulted in a reduction of staining (f), demonstrating the specificity of the observed signals. Cell nuclei were counterstained with Hoechst 33342 (c and g, blue). (d) and (h) present merged images. Scale bars in panels (d) and (h) represent $50 \mu \mathrm{m}$. 

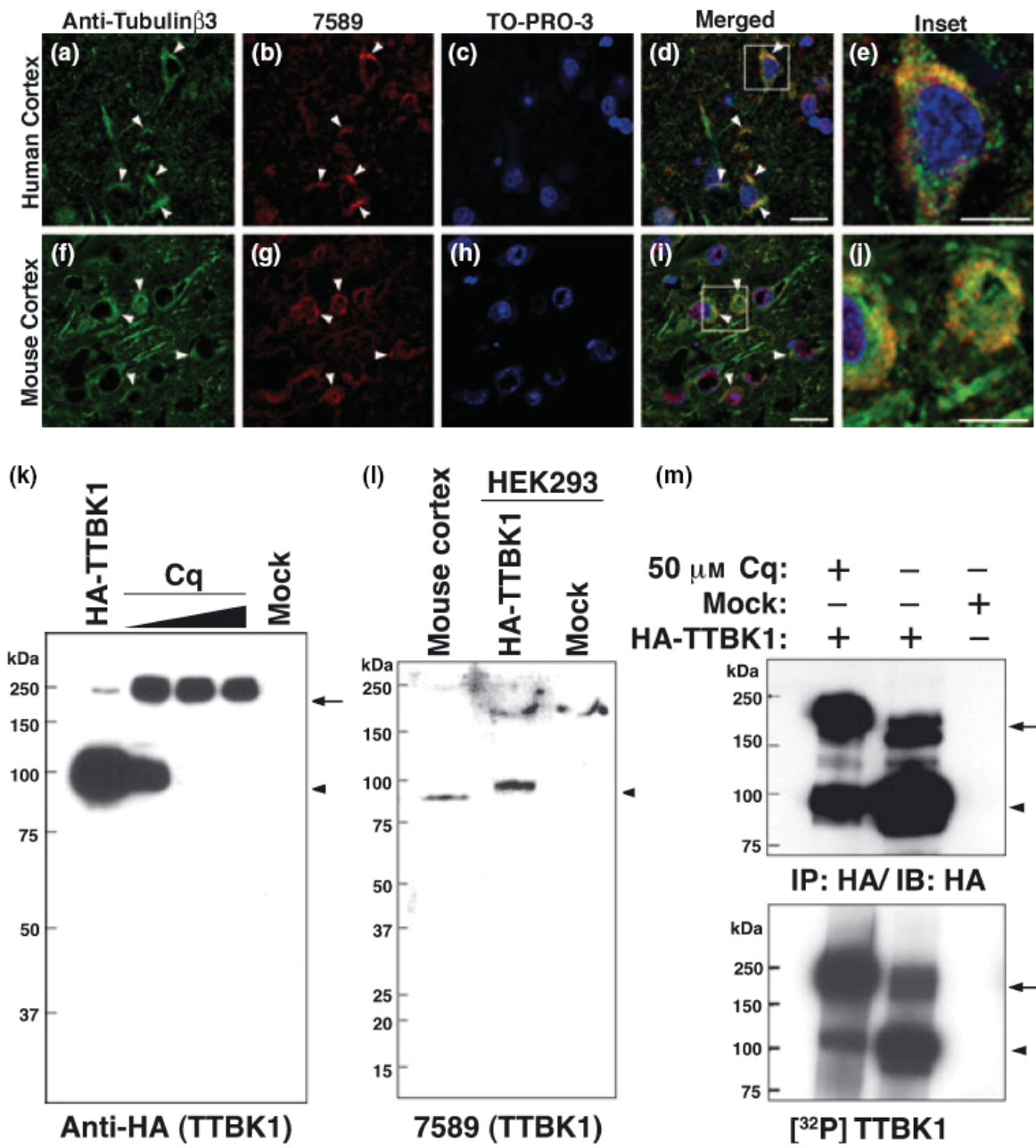

(m)
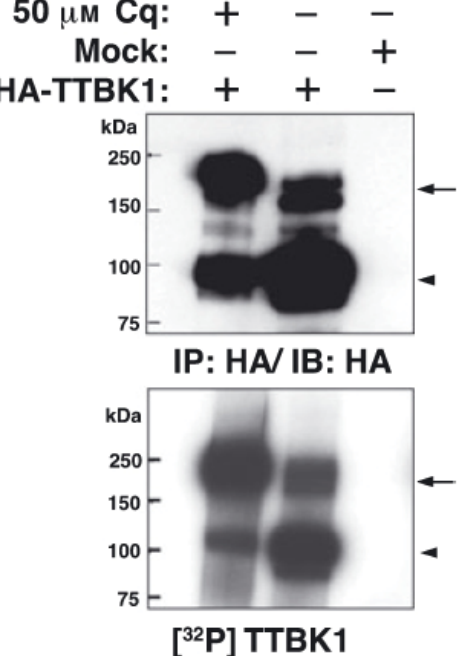

Figure 4. Immunofluorescence and immunoblotting of tau-tubulin kinase 1 (TTBK1). (a-j) Immunofluorescence of TTBK1 in brain tissues. Confocal images of human and mouse cortex double-stained with antitubulin- $\beta 3$ ( $a, d, e, f, i$ and j, green) and 7589 (b, d, e, g, i and j, red). The cell nuclei were counterstained with TO-PRO-3 (c, d, e, h, i and j, blue). The arrowheads indicate co-localization of tubulin- $\beta 3$ and 7589 immunoreactivity in cortical neurons. (d) and (i); merged images of (ac) and (f-h), respectively. (e) and (j), a higher magnification of the areas specified in (d) and (i), respectively. Scale bars: (d) and (i), $25 \mu \mathrm{m}$; (e) and (j), $10 \mu \mathrm{m}$. (k) COS-7 cells expressing either HA-TTBK1-1321 or Mock vector were treated with different concentrations of chloroquine (Cq; 10, 50 and $100 \mathrm{~mm}$ ) for $24 \mathrm{~h}$ and samples were probed

ed using anti-HA antibody, which labeled two bands at $100 \mathrm{kDa}$ and $\sim 230 \mathrm{kDa}$ (Fig. 4k, lane 1, arrowhead and arrow, respectively). Because the predicted MW of TTBK1 is $142.7 \mathrm{kDa}$, it is possible that the full-length TTBK1 migrates to $230 \mathrm{kDa}$ because of the negative charge of the polyglutamate sequence and the protein modification, and the $100-\mathrm{kDa}$ band is its proteolytic fragment resulting from protein processing.

To test this possibility, cells were incubated with chloroquine $(\mathrm{Cq})$, a lysosomal inhibitor. Cq treatment increased with anti-HA monoclonal antibody (mAb). Arrow, 230-kDa band; arrowhead, 100-kDa band. (I) Detection of TTBK1 in mouse cortical extracts $(150 \mu \mathrm{g})$ and COS-7 lysate expressing HA-TTBK1 (positive control) using anti-TTBK1 rabbit polyclonal antibody (pAb, 7589). Arrowhead, 100-kDa band of mouse TTBK1 and HA-TTBK1; *, proteolyzed HATTBK1 bands. ( $\mathrm{m}$ ) Autophosphorylation activity of TTBK1 in vitro. Immunoprecipitation of HA-TTBK1 expressed in COS-7 cells $24 \mathrm{~h}$ after treatment either with or without $50 \mu \mathrm{m} \mathrm{Cq}$ using anti-HA mAb (upper panel). Autoradiography of in vitro kinase assay using immunoprecipitated TTBK1 and [Y- $\left.{ }^{32} \mathrm{P}\right] \mathrm{ATP}-$ (lower panel). Arrows and arrowheads indicate full-length TTBK1 ( $230 \mathrm{kDa}$ ) and processed TTBK1 (100 kDa), respectively

the quantity of the $230-\mathrm{kDa}$ band with a corresponding reduction in the 100-kDa protein in a dose-dependent manner (Fig. 4k, lanes 2-4). This suggests that the $100-\mathrm{kDa}$ band is a lysosomal degradation product of full-length TTBK1.

To examine the endogenous expression of TTBK1 in mouse brain, we used the $7589 \mathrm{pAb}$ for immunoblotting (Fig. 41). The antibody detected a $100-\mathrm{kDa}$ band in mouse cortex and HA-TTBK1 expressed in HEK293 cells, but not in mock-transfected cells (Mock, Fig. 41). The MW shift is caused presumably by the tagging of TTBK1 with 
HA and myc. The absence of a $230-\mathrm{kDa}$ protein in the mouse cortex suggests a very small quantity of full-length TTBK1 as compared with the $100-\mathrm{kDa}$ fragment.

To verify that the 100 - and $230-\mathrm{kDa}$ TTBK1 have kinase activity, HA-TTBK1 was expressed in COS-7 cells treated in either the absence or the presence of $\mathrm{Cq}$ and immunoprecipitated by anti-HA antibody. The immunoprecipitated 230- and 100-kDa fragments underwent autophosphorylation as determined by the autoradiogram of incorporated $\left[{ }^{32} \mathrm{P}\right] \mathrm{O}_{4}$ (Fig. $4 \mathrm{~m}$, arrows and arrowheads, respectively), confirming that both TTBK1 forms exhibit kinase activity.

\section{TTBK1 phosphorylates tau protein in vitro}

We investigated whether the kinase catalytic domain of recombinant TTBK1 (TTBK1cat) can directly phosphorylate tau protein in vitro. Initial attempts to purify recombinant full-length TTBK1 from either Escherichia coli or baculovirus-infected sf9 insect cells were unsuccessful because of the insolubility of TTBK1. E. coli-purified TTBK1cat and $6 \times$ His-tagged human tau protein (htau40) migrate at 43 and $70 \mathrm{kDa}$ with purity greater than $90 \%$, as shown by the Coomassie Brilliant Blue staining of the protein (Fig. 5b, left-hand panel). We tested a panel of free metals to phosphorylate $6 \times$ His-tagged human tau protein by TTBK1cat. $\mathrm{Mg}^{2+}$ and $\mathrm{Mn}^{2+}$, but not $\mathrm{K}^{+}, \mathrm{Ca}^{2+}$ or $\mathrm{Zn}^{2+}$, conditions activated TTBK1 cat (data not shown). The timecourse study showed that the incorporation of ${ }^{32} \mathrm{P}$

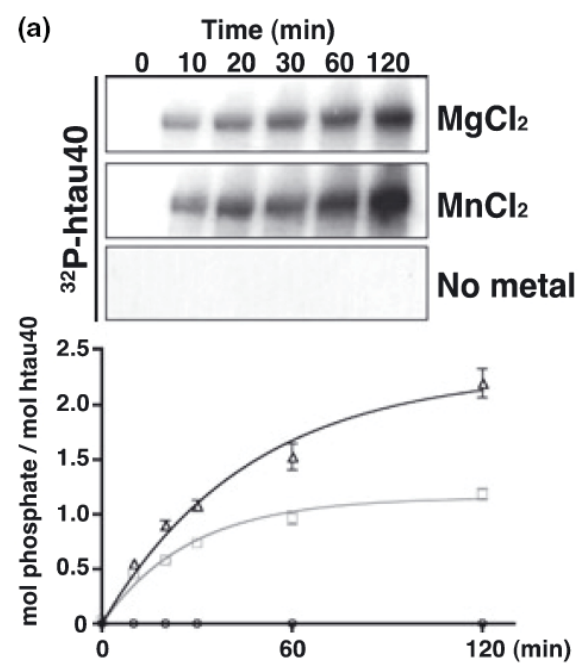

Figure 5. Tau phosphorylation by tau-tubulin kinase 1 (TTBK1) in vitro. (A) Representative kinetics of htau40 phosphorylation. (Upper panels) Autoradiography of ${ }^{32} \mathrm{P}$-incorporated htau 40 by the catalytic domain of recombinant TTBK1 (TTBK1cat) in the presence of $10 \mathrm{~mm} \mathrm{MgCl}$, $\mathrm{MnCl}_{2}$ or no metal from 0 to $120 \mathrm{~min}$. (Graph) Phosphotransfer to htau40 in the presence of $\mathrm{MnCl}_{2}(\triangle), \mathrm{MgCl}_{2}(\square)$ or no metal (०). Data were fitted to a hyperbola of GraphPad Prism v4.0. Error bars represent SD of three samples. (b) (Left-hand panel) Left lane: pre-stained into tau by TTBK1cat is faster in the presence of $\mathrm{Mn}^{2+}$ than in the presence of $\mathrm{Mg}^{2+}$ (Fig. 5a, 1.2 and $2.2 \mathrm{~mol}$ of phosphate transfer/mol of tau in the $\mathrm{Mg}^{2+}$ and $\mathrm{Mn}^{2+}$ conditions, respectively). The specific activity of TTBK1cat was 0.26 and $0.57 \mu \mathrm{mol} / \mathrm{mg} / \mathrm{min}$ in the presence of $\mathrm{Mg}^{2+}$ and $\mathrm{Mn}^{2+}$, respectively. The incubation of htau40 with TTBK1 cat caused a greater reduction in the electrophoretic mobility of htau40 than with htau 40 incubated without TTBK1 cat (Fig. 5b, right-hand panel). These data suggest that TTBK1cat directly induced phosphorylation and the electrophoretic mobility shift of htau40 in vitro.

\section{Identification of phosphorylated amino acid of tau by tandem mass spectrometry}

We determined the exact htau 40 phosphorylation sites in vitro by phosphopeptide mapping using liquid chromatography and tandem mass-spectrometry (LC/MS/MS). The LC/ MS/MS data covered $71 \%$ of the recombinant htau 40 sequence, and the possible phosphorylation sites are listed in Table 1. Both $\mathrm{Mg}^{2+}$ and $\mathrm{Mg}^{2+}$ conditions identified htau40 phosphorylation at Tyr197, Ser198, Ser199, Ser202 and Ser422 sites, which have all been reported to be phosphorylated in PHF-tau (Iqbal et al. 1989; Morishima-Kawashima et al. 1995a,b; Hanger et al. 1998; Vega et al. 2005). Ser416 and Thr427 are new sites, and Thr427 phosphorylation was observed under both $\mathrm{Mg}^{2+}$ and $\mathrm{Mn}^{2+}$ conditions. These results suggest that TTBK1 is a critical enzyme for the phosphorylation of PHF-specific sites of tau protein.

(b)

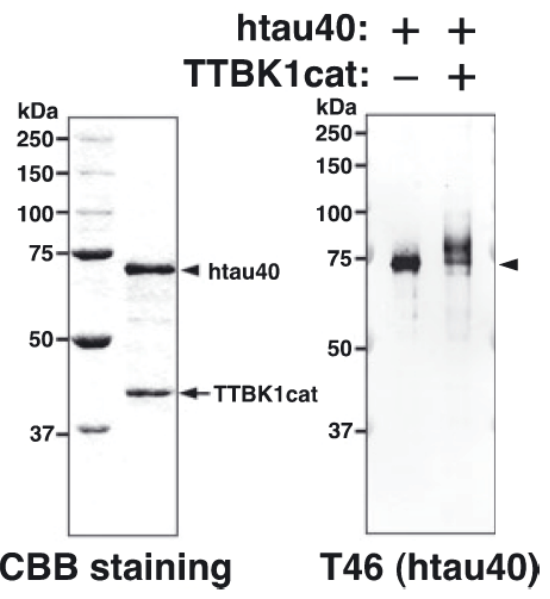

molecular marker. Right lane: Coomassie Brilliant Blue R-250 staining of purified $6 \times$ His-tagged TTBK1cat $(43 \mathrm{kDa}$; see Materials and methods for the purification procedure) and $6 \times$ His-tagged htau40 (70 kDa, purchased from Calbiochem). (Right panel) Immunoblotting of total htau40 (50 ng) using T46 monoclonal antibody (mAb) after overnight incubation either with or without TTBK1cat $(50 \mathrm{ng})$ with $10 \mathrm{~mm} \mathrm{MnCl}$. Arrowhead, original molecular weight of htau 40 . 
Table 1 Identification of phosphorylation sites on TTBK1-phosphorylated htau40 (upper; $\mathrm{MgCl}_{2}$, lower; $\mathrm{MnCl}_{2}$ )

\begin{tabular}{|c|c|c|c|c|c|c|}
\hline $\mathrm{MS}^{1} \mathrm{ID}$ & Residues $^{a}$ & Mass (calc.) & Score & Delta & $\mathrm{MS}^{2}$ peptide sequence & Phosphorylated site(s) \\
\hline \multirow[t]{2}{*}{107} & 197-209 & 1408.51 & 62.2 & 0.11 & YSSPGSPGTPGSR & $\mathrm{Y} 197^{\mathrm{b}}, \mathrm{S} 198^{\mathrm{b}}$ \\
\hline & $197-209$ & 1408.51 & 32.2 & 0.11 & $\overline{Y S} \underline{S} P G \underline{S} P G T P G S R$ & $\mathrm{~S} 199^{\mathrm{b}}, \mathrm{S} 202^{\mathrm{b}}$ \\
\hline 269 & 407-437 & 32744.44 & 19.2 & 0.17 & HLS̄NVS̄STGSIDMVDŚPQLATLADEVSASLA & $\mathrm{S} 422^{\mathrm{b}}, \mathrm{T} 427$ \\
\hline \multirow[t]{2}{*}{95} & 197-209 & 1408.51 & 49.6 & 0.10 & YSSPGSPGTPGSR & $\mathrm{Y} 197^{\mathrm{b}}, \mathrm{S} 198^{\mathrm{b}}$ \\
\hline & 197-209 & 1408.51 & 21.7 & 0.1 & $\overline{Y S} \underline{S P G S P G T P G S R}$ & $\mathrm{~S} 199^{\mathrm{b}}, \mathrm{S} 202^{\mathrm{b}}$ \\
\hline 279 & $407-428$ & 2527.00 & 27.3 & 0.09 & HLSNVSSTGSIDMVDSPPQATL & $\mathrm{S} 416, \mathrm{~S} 422^{\mathrm{b}}, \mathrm{T} 427$ \\
\hline
\end{tabular}

Underlines indicate phosphorylated serine $(\mathrm{S})$, threonine $(\mathrm{T})$, or tyrosine $(\mathrm{Y})$.

${ }^{a}$ Numbering of the largest human tau isoform (Goedert et al., 1989).

'Identified in PHF-tau (Iqbal et al., 1989, Morishima-Kawashima et al., 1995a,b, Hanger et al., 1998, Vega et al., 2005).

\section{TTBK1 induces multiple tau phosphorylation and aggregation}

To test whether the tau phosphorylation sites identified by phosphopeptide mapping are actually phosphorylated by full-length TTBK1 in tissue-cultured cells, htau40 and full-length HA-TTBK1 were transiently co-expressed in COS-7 cells for immunoblotting analysis (Fig. 6a). Detection of total tau protein using the tau antibody T46, the reactivity of which is phosphorylation independent (Kosik et al. 1988), revealed a substantial electrophoretic mobility shift of tau induced by TTBK1 expression (Fig. 6a, right-hand upper panel). Co-expression of htau40 and TTBK1 resulted in multiple tau phosphorylations as detected by specific antibodies, AT8 (Ser199, Ser202 and Thr205 specific), CP13 (Ser202 specific) and
pS422 (Ser422 specific). Thus, the htau40 phosphorylation by TTBK1 at Ser199, Ser202 and Ser422 were confirmed both in vitro and in intact cell systems. Importantly, pS422 is a PHF-tau specific antibody (Hasegawa et al. 1992; Zheng-Fischhofer et al. 1998). We could not detect Tyr-phosphorylation of htau 40 by using anti-phospho-Tyr antibodies (PY20, 4G10 and rabbit polyclonals, data not shown). This could be caused by the presence of negatively charged either phospho-Ser198 or phospho-Ser199, which might interfere with the interaction of phospho-Tyr197 with anti-phospho-Tyr antibodies.

Because tau phosphorylation is closely related to its aggregation, we investigated whether the over-expression of TTBK1 induced htau40 aggregation in human neuronal cells (SH-SY5Y, Fig. 5b). Co-infection of SH-SY5Y (a)

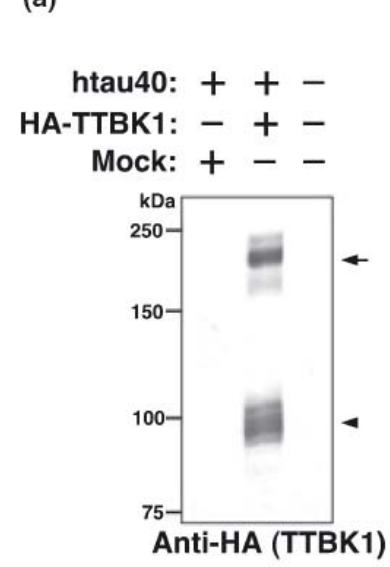

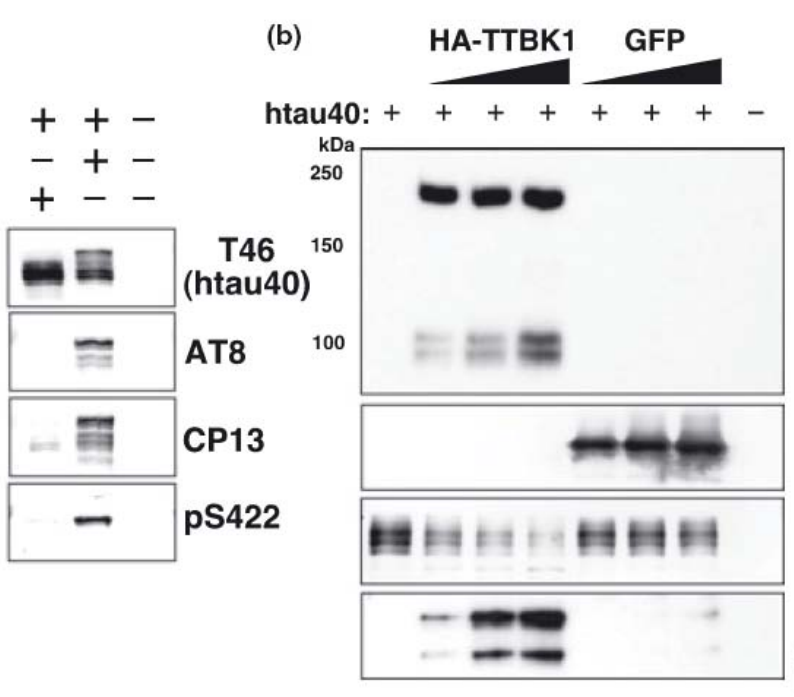

Anti-HA

(TTBK1)

Anti-GFP

Tau-5

(Sup)

Tau-5

(Sarkosyl

insoluble)
Figure 6. Tau-tubulin kinase 1 (TTBK1)-induced tau phosphorylation and aggregation in cultured cells, and its expression in the Alzheimer's disease (AD) brain. (a) Phosphorylation of htau40 by HA-TTBK1 in COS-7 cells. (Left-hand panel) HA-TTBK1 bands at 230 and $100 \mathrm{kDa}$ are indicated by an arrow and an arrowhead, respectively. (Right-hand panels) Detection of total htau40 (T46), its phosphorylation at Ser199,
Ser202 and Thr205 (AT8), Ser202 (CP13) and Ser422 (pS422). (b) Tau aggregation induced by TTBK1 expression in SH-SY5Y human neuroblastoma cells. Sucrose supernatant protein samples were run on SDS-PAGE and immunoblotted using anti-HA (TTBK1), anti-GFP and Tau-5, respectively. Sarkosyl-insoluble (SI) fractions were immunoblotted using Tau-5. 
cells with adenovirus expressing wild-type htau 40 and increasing titer of adenovirus expressing HA-TTBK1 resulted in a reduction of sucrose supernatant htau40 (Sup) and the accumulation of a sarkosyl-insoluble fraction of htau40 (Sarkosyl insoluble; Fig. 6b). Control co-infection with an increasing titer of GFP-expressing adenovirus had no effect on tau aggregation. These data demonstrated that TTBK1 significantly increased the tau insolubility in human neuronal cells. These data support the idea that TTBK1 is involved in tau phosphorylation and aggregation in an intact cell system.

\section{Discussion}

TTBK1 is a unique protein because it has dual kinase activity on human tau protein and is specifically expressed in neurons. The tissue and brain specificity of TTBK 1 expression has been confirmed by northern blotting, in situ hybridization and immunohistochemistry of human and mouse brains using specific 7589 pAb against TTBK1. The expression of HA-tagged full-length TTBK1 was mainly cytoplasmic, which is consistent with its endogenous, neuron-specific expression in human and mouse cortex. We have also confirmed two distinct fragments of TTBK1 when expressed in COS-7 cells. The discrepancy in the predicted molecular weight $(142 \mathrm{kDa})$ and apparent size $(230 \mathrm{kDa})$ of full-length TTBK1 on SDSPAGE could be a result of either multiple phosphorylations of TTBK1 or the negative charge of the polyglutamate domain. Similar abnormal migration was found in middle MW neurofilaments (NF-M), which also contain a polyglutamate domain and have multiple phosphorylation sites (Napolitano et al. 1987). This discrepancy requires further analysis either by treating the protein sample with protein phosphatase or through deleting the polyglutamate region of TTBK1 to see if these manipulations alter the electrophoresis of the TTBK1 protein.

TTBK1 appears to undergo a post-translational modification by limited lysosomal processing to generate a 100 $\mathrm{kDa}$ fragment, which contains the dual kinase domain and non-catalytic region. This is specific to lysosomes as $\mathrm{Cq}$, a lysosomal inhibitor, blocked endoproteolysis and MG132, a potent proteasome inhibitor, had no effect on the accumulation of a full-length TTBK1 (data not shown). Interestingly, TTBK1 has seven possible PEST sequences, which are defined as hydrophilic stretches of amino acids either greater than or equal to 12 residues in length, which contain at least one Pro, one Glu or Asp, and one Ser or Thr (Rechsteiner and Rogers 1996). The PESTfind program identified amino acids 436-447, 528-541, 553-575, 626-640, 819-834, 1003-1036 and 1119-1144 as possible PEST sequences (Rogers et al. 1986). Whether the putative PEST sequences of TTBK1 are functional and required for the lysosome-mediated degradation will be explored in future studies. Currently under investigation is whether the polyglutamate region remains in the 100$\mathrm{kDa}$ form. We have also detected an endogenous $100-\mathrm{kDa}$ form of TTBK1 in mouse brains, which is also found in SH-SY5Y cells (data not shown).

Fyn and c-Abl have been reported to phosphorylate tau protein at Tyr18 and Try394, respectively (Lee et al. 2004; Derkinderen et al. 2005). TTBK1 is the first kinase that can directly phosphorylate Tyr197 in vitro, although we could not confirm it in an intact cell system. Among other TTBK1-mediated phosphorylation sites, Ser422 is of particular interest because it appears to be highly specific for PHF-tau (Hasegawa et al. 1996; Zheng-Fischhofer et al. 1998), and is critically involved in tau aggregation in SH-SY5Y cells (Pennanen and Gotz 2005).

In addition to phosphorylation, TTBK1 induces htau40 aggregation in SH-SY5Y cells. A reduction of the sucrose supernatant fraction of htau40 is correlated with the accumulation of the sarkosyl-insoluble fraction, demonstrating that the majority of htau 40 is in the insoluble fraction by TTBK1 expression. TTBK1 phosphorylates residues critical for tau aggregation in SH-SY5Y cells (Ser202 and Ser422, among others; Pennanen and Gotz 2005), demonstrating that TTBK1 activation enhances tau aggregation through its phosphorylation.

In summary, TTBK1 is a brain-specific protein kinase, specifically expressed in neuronal cells, phosphorylates tau protein at multiple PHF-tau-related residues in vitro and in intact cell systems, and induces tau aggregation. TTBK1 may play an important role in neural tau phosphorylation and aggregation. Further studies are necessary to elucidate the molecular mechanism of TTBK1 expression, processing, activation and intracellular signaling in neurons.

\section{Acknowledgements}

We are grateful to Drs Y. Ihara, G. Lee, A. Ghorpade, D. Middlemas and H. Gendelman for the critical reading of the manuscript, Dr A. Takashima for supplying us with recombinant adenoviral vectors and constructive suggestions, Dr P. Davies for the supply of CP13, Dr A. Delacourte for the supply of pS422, H. Paudel for the supply of tau cDNA, B. Vogelstein for the supply of the AdEasy system and Kazusa DNA Research Institute for KIAA1855 cDNA. This work was supported by the UNMC Start-up Fund (TI) and Vada Oldfield Alzheimer's Research Awards (TI and SS), John Douglas French Alzheimer's Foundation Fellowship (SS), NCRR Grant P20 RR15635, NIH P30 CA36727 and the Nebraska Research Initiative (RLC). TTBK1/BDTK GenBank ID: AB218664; US patent pending. 


\section{References}

Alonso A. C., Grundke-Iqbal I. and Iqbal K. (1996) Alzheimer's disease hyperphosphorylated tau sequesters normal tau into tangles of filaments and disassembles microtubules. Nat. Med. 2, 783787.

Alonso A., Zaidi T., Novak M., Grundke-Iqbal I. and Iqbal K. (2001) Hyperphosphorylation induces self-assembly of tau into tangles of paired helical filaments/straight filaments. Proc. Natl Acad. Sci. USA 98, 6923-6928.

Arioka M., Tsukamoto M., Ishiguro K., Kato R., Sato K., Imahori K. and Uchida T. (1993) Tau protein kinase II is involved in the regulation of the normal phosphorylation state of tau protein. J. Neurochem. 60, 461-468.

Bhaskar K., Yen S. H. and Lee G. (2005) Disease-related modifications in tau affect the interaction between Fyn and Tau. J. Biol. Chem. 280, 35 119-35 125.

Biernat J., Gustke N., Drewes G., Mandelkow E. M. and Mandelkow E. (1993) Phosphorylation of Ser262 strongly reduces binding of tau to microtubules: distinction between PHF-like immunoreactivity and microtubule binding. Neuron 11, 153-163.

Bramblett G. T., Goedert M., Jakes R., Merrick S. E., Trojanowski J. Q. and Lee V. M. (1993) Abnormal tau phosphorylation at Ser396 in Alzheimer's disease recapitulates development and contributes to reduced microtubule binding. Neuron 10, 1089-1099.

Buee L., Bussiere T., Buee-Scherrer V., Delacourte A. and Hof P. R. (2000) Tau protein isoforms, phosphorylation and role in neurodegenerative disorders. Brain Res. Brain Res. Rev. 33, 95-130.

Derkinderen P., Scales T. M., Hanger D. P., et al. (2005) Tyrosine 394 is phosphorylated in Alzheimer's paired helical filament tau and in fetal tau with c-Abl as the candidate tyrosine kinase. J. Neurosci. $25,6584-6593$.

Goedert M., Spillantini M. G., Cairns N. J. and Crowther R. A. (1992) Tau proteins of Alzheimer paired helical filaments: abnormal phosphorylation of all six brain isoforms. Neuron 8, 159168.

Grundke-Iqbal I., Iqbal K., Tung Y. C., Quinlan M., Wisniewski H. M. and Binder L. I. (1986) Abnormal phosphorylation of the microtubule-associated protein tau (tau) in Alzheimer cytoskeletal pathology. Proc. Natl Acad. Sci. USA 83, 4913-4917.

Hanger D. P., Betts J. C., Loviny T. L., Blackstock W. P. and Anderton B. H. (1998) New phosphorylation sites identified in hyperphosphorylated tau (paired helical filament-tau) from Alzheimer's disease brain using nanoelectrospray mass spectrometry. J. Neurochem. 71, 2465-2476.

Hasegawa M., Morishima-Kawashima M., Takio K., Suzuki M., Titani K. and Ihara Y. (1992) Protein sequence and mass spectrometric analyses of tau in the Alzheimer's disease brain. J. Biol. Chem. 267, 17 047-17 054.

Hasegawa M., Jakes R., Crowther R. A., Lee V. M., Ihara Y. and Goedert M. (1996) Characterization of mAb AP422, a novel phosphorylation-dependent monoclonal antibody against tau protein. FEBS Lett. 384, 25-30.

He T. C., Zhou S., da Costa L. T. YuJ., Kinzler K. W. and Vogelstein B. (1998) A simplified system for generating recombinant adenoviruses. Proc. Natl Acad. Sci. USA 95, 2509-2514.

Hutton M., Lendon C. L., Rizzu P., et al. (1998) Association of mis- sense and 5'-splice-site mutations in tau with the inherited dementia FTDP-17. Nature 393, 702-705.

Ikezu T., Luo X., Weber G. A., Zhao J., McCabe L., Buescher J. L., Ghorpade A., Zheng J. and Xiong H. (2003) Amyloid precursor protein-processing products affect mononuclear phagocyte activation: pathways for sAPP- and Abeta-mediated neurotoxicity. J. Neurochem. 85, 925-934.

Imahori K. and Uchida T. (1997) Physiology and pathology of tau protein kinases in relation to Alzheimer's disease. J. Biochem. (Tokyo) 121, 179-188.

Iqbal K., Grundke-Iqbal I., Smith A. J., George L., Tung Y. C. and Zaidi T. (1989) Identification and localization of a tau peptide to paired helical filaments of Alzheimer disease. Proc. Natl Acad. Sci. USA 86, 5646-5650.

Ishiguro K., Omori A., Takamatsu M., Sato K., Arioka M., Uchida T. and Imahori K. (1992) Phosphorylation sites on tau by tau protein kinase I, a bovine derived kinase generating an epitope of paired helical filaments. Neurosci. Lett. 148, 202-206.

Jackson G. R., Wiedau-Pazos M., Sang T. K., Wagle N., Brown C. A., Massachi S. and Geschwind D. H. (2002) Human wild-type tau interacts with wingless pathway components and produces neurofibrillary pathology in Drosophila. Neuron 34, 509-519.

Kayser J. P., Vallet J. L. and Cerny R. L. (2004) Defining parameters for homology-tolerant database searching. J. Biomol. Tech $15,285-295$.

Kosik K. S., Orecchio L. D., Binder L., Trojanowski J. Q., Lee V. M. and Lee G. (1988) Epitopes that span the tau molecule are shared with paired helical filaments. Neuron 1, 817-825.

Kozak M. (1986) Point mutations define a sequence flanking the AUG initiator codon that modulates translation by eukaryotic ribosomes. Cell 44, 283-292.

Lee V. M., Goedert M. and Trojanowski J. Q. (2001) Neurodegenerative tauopathies. Annu. Rev. Neurosci. 24, 1121-1159.

Lee G., Thangavel R., Sharma V. M., Litersky J. M., Bhaskar K., Fang S. M., Do L. H., Andreadis A., Van Hoesen G. and KsiezakReding H. (2004) Phosphorylation of tau by fyn: implications for Alzheimer's disease. J. Neurosci. 24, 2304-2312.

Li G., Yin H. and Kuret J. (2004) Casein kinase 1 delta phosphorylates tau and disrupts its binding to microtubules. J. Biol. Chem. 279, 15 938-15945.

Manning G., Whyte D. B., Martinez R., Hunter T. and Sudarsanam S. (2002) The protein kinase complement of the human genome. Science 298, 1912-1934.

Morishima-Kawashima M., Hasegawa M., Takio K., Suzuki M., Yoshida H., Titani K. and Ihara Y. (1995a) Proline-directed and non-proline-directed phosphorylation of PHF-tau. J. Biol. Chem. 270, 823-829.

Morishima-Kawashima M., Hasegawa M., Takio K., Suzuki M., Yoshida H., Watanabe A., Titani K. and Ihara Y. (1995b) Hyperphosphorylation of tau in PHF. Neurobiol. Aging 16, 365-371 (discussion 371-380).

Napolitano E. W., Chin S. S., Colman D. R. and Liem R. K. (1987) Complete amino acid sequence and in vitro expression of rat NF$\mathrm{M}$, the middle molecular weight neurofilament protein. J. Neurosci. 7, 2590-2599.

Noble W., Olm V., Takata K., et al. (2003) Cdk5 is a key factor in tau aggregation and tangle formation in vivo. Neuron 38, 555-565. 
Patrick G. N., Zukerberg L., Nikolic M., de la Monte S., Dikkes P. and Tsai L. H. (1999) Conversion of $\mathrm{p} 35$ to $\mathrm{p} 25$ deregulates Cdk5 activity and promotes neurodegeneration. Nature 402, 615-622.

Pennanen L. and Gotz J. (2005) Different tau epitopes define Abeta (42)-mediated tau insolubility. Biochem. Biophys. Res. Commun. 337, 1097-1101.

Planel E., Sun X. and Takashima A. (2002) Role of GSK-3 $\beta$ in Alzheimer's disease pathology. Drug Dev Res. 56, 491-510.

Rechsteiner M. and Rogers S. W. (1996) PEST sequences and regulation by proteolysis. Trends Biochem. Sci. 21, 267-271.

Rogers S., Wells R. and Rechsteiner M. (1986) Amino acid sequences common to rapidly degraded proteins: the PEST hypothesis. Science 234, 364-368.

Sato S., Tatebayashi Y., Akagi T., et al. (2002) Aberrant tau phosphorylation by glycogen synthase kinase-3beta and JNK3 induces oligomeric tau fibrils in COS-7 cells. J. Biol. Chem. 277, $42060-42065$.

Sun A., Nguyen X. V. and Bing G. (2002) Comparative analysis of an improved thioflavin-s stain, Gallyas silver stain, and immunohistochemistry for neurofibrillary tangle demonstration on the same sections. J. Histochem. Cytochem. 50, 463-472.

Thompson J. D., Higgins D. G. and Gibson T. J. (1994) CLUSTAL $\mathrm{W}$ : improving the sensitivity of progressive multiple sequence alignment through sequence weighting, position-specific gap penalties and weight matrix choice. Nucl. Acids Res. 22, 46734680 .

Tomizawa K., Omori A., Ohtake A., Sato K. and Takahashi M. (2001) Tau-tubulin kinase phosphorylates tau at Ser-208 and Ser210, sites found in paired helical filament-tau. FEBS Lett. 492, 221-227.

Vega I. E., Cui L., Propst J. A., Hutton M. L., Lee G. and Yen S. H. (2005) Increase in tau tyrosine phosphorylation correlates with the formation of tau aggregates. Brain Res. Mol. Brain Res. 138, $135-144$.

Yamamoto M., Horiba M., Buescher J. L., Huang D., Gendelman H. E., Ransohoff R. M. and Ikezu T. (2005) Overexpression of monocyte chemotactic protein-1/CCL2 in beta-amyloid precursor protein transgenic mice show accelerated diffuse beta-amyloid deposition. Am. J. Pathol. 166, 1475-1485.

Zheng-Fischhofer Q., Biernat J., Mandelkow E. M., Illenberger S., Godemann R. and Mandelkow E. (1998) Sequential phosphorylation of Tau by glycogen synthase kinase-3beta and protein kinase A at Thr212 and Ser214 generates the Alzheimer-specific epitope of antibody AT100 and requires a paired-helical-filamentlike conformation. Eur. J. Biochem. 252, 542-552. 